\title{
IS THE INTERPLAY BETWEEN SELF-EFFICACY AND ENTREPRENEURIAL INTENTION GENDER-DEPENDENT? ${ }^{1}$
}

The aim of the study is to investigate whether the interplay between entrepreneurial intentions and self-efficacy depends on gender. As males still dominate worldwide in entrepreneurial activity, the authors are interested in the specifics of female entrepreneurship and its antecedents. The central hypothesis was that female students have lower self-efficacy than male students which induces lower intentions towards venture creation. To follow the research aims, the authors conducted a questionnaire among students at one of the Polish universities. It included questions relating to the concept of self-efficacy inspired by the works of Bandura (1977, 1982, 1986, 1989), Noble et al. (1999) and Boyd and Vozikis (1994). By using various statistical methods (including the two means t-test, the coefficient of correlation test, the Chi-squared independence test and the Mann-Whitney $U$ test) the interplay between intentions, gender and self-efficacy was investigated. According to the findings, the level of entrepreneurial intentions is gender-dependent and men present higher intentions towards venture creation than women. However, entrepreneurial self-efficacy proved to be not related to gender and self-efficacy is not a major factor shaping entrepreneurial intentions. The reason for lower intentions among women is not significantly connected with their self-efficacy. The paper discusses the contextual meaning of the results and their implications for entrepreneurship education in Poland.

Keywords: entrepreneurial intentions, self-efficacy, entrepreneurial education, gender, Poland

DOI: $10.15611 /$ aoe.2014.2.02

\section{INTRODUCTION}

The discussion on the intentions in entrepreneurship research has been attracting the attention of scholars for more than thirty years. Intentions have recently become a research field which promised to help us better understand the phenomenon of entrepreneurial activity and provided some answers to a

\footnotetext{
* Faculty of Economics and Sociology, University of Lodz, Poland

${ }^{1}$ The first version of the paper was presented during the International Council for Small Business (ICSB) World Conference in Ponce (Puerto Rico) in June 2013. The authors are grateful for all comments received from the ICSB attendees and also the comments from two anonymous reviewers.
} 
basic question in entrepreneurship research: what makes individuals more entrepreneurial? In the beginning the research efforts were directed towards building models of entrepreneurial intentions (Shapero and Sokol 1982, Bird 1988) and testing ones deriving from psychology (Ajzen 1991), then combining these models (Krueger and Brazeal 1994, Iakovleva and Kolvereid 2009) and finally matching them with other concepts from entrepreneurship research (like social network and experience - Xiaohong 2012, or education Liñán 2004). As a result, among the key antecedents of entrepreneurial intentions the researchers identified perceived feasibility (connected with individuals' beliefs about success in becoming an entrepreneur) and perceived desirability (related to the extent to which being an entrepreneur is a justified and preferred career path for them). This perception has started to be regarded as a function of entrepreneurial intentions. It is responsible for receiving information from the environment, but also is related to the concept of selfperception, which means being aware of the characteristics that constitute one's self, and even further to self-concept, or the perception of a "self". In the context of entrepreneurial intentions, perception guides individuals in their entrepreneurial beliefs and attitudes.

At the time when entrepreneurial intentions first began to appear in research work, the psychologist Bandura (1977, 1982, 1986, 1989) developed within social cognitive theory the concept of self-efficacy, typically defined as "the belief in one's capabilities to organize and execute the courses of action required to manage prospective situations" (Bandura 1995, p. 2). The concept was shortly transposed to entrepreneurship research. Self-efficacy is developed from self-perception and, in the context of entrepreneurship, concerns one's own skills to become successful in terms of venture creation. As self-confidence is related to perception and perception is linked with intentions, scholars started to investigate the interplay between self-efficacy and entrepreneurial intentions. Recent research shows that there is a positive relationship between these two concepts (for example Zhao et al. 2005, McGee et al. 2009).

However, there is also evidence on the differences between the genders in terms of self-efficacy and in terms of intensity of entrepreneurial intentions. Women appear to be more dependent in their choices and less confident in taking decisions (Bandura 1992) and thus in general show less self-efficacy then men. Also, worldwide, women participate in venture creation less. The Global Entrepreneurship Monitor's (GEM 2010) special report on women entrepreneurship reveals that women on average manifest lower perceptions about opportunities and capabilities, lower intentions and a higher fear of 
failure than men. Thus the reason for the lower activity of women in entrepreneurship and their lower entrepreneurial intentions could has its roots in their lower self-efficacy. The idea of the study is to follow this track and investigate whether the interplay between entrepreneurial intentions and self-efficacy really depends on gender.

We are especially motivated by the GEM report (2010, p. 42) findings suggesting that: "In societies where women believe they have the capabilities for entrepreneurship, they are more likely to see opportunities for starting businesses. To the extent that this is true, it calls to attention the importance of developing women's capabilities and their confidence in their abilities.” By uncovering the relationships between students' entrepreneurial intentions, selfefficacy and gender, we are interested in identifying the differences in young women's and men's perceptions of entrepreneurship and their antecedents, which lead to some ideas about introducing entrepreneurship education empowering young women. In other words, our study enables us to be closer to the answer of whether the way to increase entrepreneurial intentions among women may be achieved through developing their self-efficacy.

In order to follow our research aims we conducted a questionnaire on entrepreneurial intentions. The questionnaire was distributed among students at one of the biggest Polish universities, the University of Lodz. The questionnaire included questions relating to the concept of self-efficacy. Our central hypothesis was that female students have lower self-efficacy than male students which induces lower intentions towards venture creation. By using various statistical methods (including the two means t-test, the coefficient of correlation test, the Chi-squared independence test and the Mann-Whitney U test) we investigated the interplay between intentions, gender and self-efficacy.

Determining the influence of gender on self-efficacy and entrepreneurial intentions in a group of Polish students has its contextual meaning. Poland is a country full of contrasts when it comes to entrepreneurship. The country's level of female entrepreneurship is comparable to the European Union average and Polish female entrepreneurs are better educated than male entrepreneurs (PARP 2011). However, women-owned companies are in general smaller, employ fewer staff and are less visible on the market. What is also striking is that Poland has the highest rate of necessity-driven entrepreneurship in the European Union (41\% of the total entrepreneurial activity) and at the same time Polish entrepreneurs have a high perception of their own capabilities in comparison with other EU countries (GEM 2012). Surprisingly, compared to Polish men, women are more opportunity-than necessity-driven in their entrepreneurial ventures. The study's ambition is to contribute to a better understanding of these paradoxes. 


\section{THEORETICAL CONSIDERATIONS}

Since the rise of entrepreneurship field, researchers have been trying to identify the determinants of entrepreneurial behaviour. The decision to take risk and exploit a business opportunity is linked to economic factors like: market size and growth, business type, sector, geographical location etc. However, entrepreneurial behaviour cannot be explained only by institutional and economic variables. It is influenced by the profile of an entrepreneur, an active human being who is pursuing opportunities in order to exploit them. This means that non-economic factors also have to be included if we want to understand the phenomenon of entrepreneurship. In this paper we take an individual, rooted in cognitive school, approach to the determinants of entrepreneurial behaviour. We focus on individuals and their entrepreneurial intentions which we believe are the best predictors of entrepreneurial behaviour. However, we do not follow seminal models of entrepreneurial intentions (like the Theory of Planned Behaviour of Ajzen or the Model of the Entrepreneurial Event of Shapero and Sokol, or their modifications), but rather try to combine elements of these models in order to examine the role of self-efficacy in entrepreneurial processes. As a core phenomenon we decided to investigate whether the interplay between selfefficacy and entrepreneurial intentions is gender-dependent.

As a result, this paper includes a theoretical discussion on self-efficacy as a part of self-perception that influences behaviour, self-efficacy as an antecedent of entrepreneurial intentions, as well as on an interplay between entrepreneurial intentions and gender, and self-efficacy and gender.

\section{Self-efficacy as a part of self-perception that influences behaviour}

Self-efficacy is a part of the self-system an individual uses. It is the belief of an individual in own ability to attain a particular goal/behaviour. The selfefficacy concept is part of the social cognitive theory, the theory explaining how people acquire and maintain certain behavioural patterns (Bandura 1997). Bandura (1986, p.391) defines self-efficacy as "people's judgments of their capabilities to organize and execute courses of action required to attain designated types of performances to the extent that their level of motivation, affective states and actions are based more on what they believe than on what is objectively true". As Bandura demonstrates, self-efficacy impacts on behaviour and is an important precondition for behaviour change. Efficacy beliefs have an influence on how individuals feel, think, motivate themselves and behave (Bandura 1993). The formation of self-efficacy is also connected with one's assessment of the availability of resources and constraints to 
achieve a given performance. Individuals with high self-efficacy are more likely to perceive tasks as to be learned or experienced rather than to be avoided. Importantly, self-efficacy might be used to predict behaviour.

Self-efficacy differs from locus of control as it refers to specific situations or tasks (Boyd and Vozikis 1994) and applies more to competences. That is why it is also different from self-esteem. Importantly, as Boyd et Vozikis (1994) notice, self-efficacy refers to a person's judgment of his or her ability to execute a certain behaviour pattern, rather than the likelihood that the behaviour will lead to certain consequences.

Self-efficacy is task-specific, thus in the case of entrepreneurship we can talk about entrepreneurial self-efficacy, meaning an individual's perception that he/she can create a venture and become an entrepreneur. As Noble et al. (1999) claim: "By definition, an entrepreneur with a high level of selfefficacy, who truly believes in his or her capability to execute all of the requirements to perform a task successfully is more likely to see the positive potential outcomes that might accrue from a new venture”. The role of selfefficacy has been confirmed for example in work organizations (Stajkovic and Luthans 1998) and linked with the performance of entrepreneurs (Chen et al. 1998).

In light of the above, self-efficacy might be helpful in understanding why some individuals become entrepreneurs as, applying the social cognitive theory to entrepreneurship research, individuals with higher entrepreneurial self-efficacy believe that they are able to complete the venture creation process.

\section{Self-efficacy as an antecedent of entrepreneurial intentions}

Starting with Boyd and Vozikis' theoretical framework (1994), entrepreneurship research launched an investigation into the role selfefficacy in the venture creation process. The self-efficacy concept started to appear in the entrepreneurship field by being embedded in models of entrepreneurial intentions. Both concepts belong to a cognitive stream of discussion in entrepreneurship and both seem to be good predictors of entrepreneurial behaviour. Boyd and Vozikis enriched Bird's (1988) model of entrepreneurial intentionality by adding an individual's concept of selfefficacy. In further research, self-efficacy may be found also in other models of entrepreneurial intentions. Perceived feasibility from the Shapero's model corresponds to the self-efficacy concept. Boyd and Vozikis (1994) define self-efficacy as an individual's belief in his/her own capabilities to complete tasks. Thus the meaning of the two is close. Self-efficacy is a proxy for perceived feasibility (Segal et al. 2005). Self-efficacy relates also to 
perceived behavioural control in Ajzen's theory of planned behaviour. Ajzen in his later works (2002), developed perceived control over behaviour and highlighted its importance for intentions.

The relation between self-efficacy and intentions has been already investigated by many authors. Although some of them find a negative relation between these two concepts (Sequeira et al. 2005, Mueller and Conway Dato-On 2008), the positive influence of self-efficacy on the level of entrepreneurial intentions prevails (DeNoble et al. 1999). Among studies confirming the positive relation between self-efficacy and entrepreneurial intentions are, for example, McGee et al. (2009) and Zhao et al. (2005).

In light of the above, the level of self-efficacy influences the level of entrepreneurial intentions. When self-efficacy is low, individuals are less eager to act, so the intentions for behaviour are low.

\section{Entrepreneurial intentions and gender}

According to the research of Langowitz and Minniti (2007), women in general express less positive perceptions about themselves and the environment. The reasons for resistance in starting up a business are presumed to stem from a higher fear of failure (Wagner 2007) or a lower perception of self-efficacy for careers, especially in professions where women are underrepresented (Scherer et al. 1990).

In light of previous research, we can assume that entrepreneurial intentions among women appear to be lower than among men.

\section{Self-efficacy and gender}

The attainment of a given behaviour might be gender-dependent. Nevertheless, researchers investigating that interplay come to very contrary findings. It very much depends on the area of self-efficacy. In the entrepreneurship context, Zhao et al. (2005), Wilson et al. (2007) and Nwankwo et al. (2012) do not find a relation between entrepreneurial selfefficacy and gender, whereas for example Scherer's (1990) research confirmed it. However, entrepreneurship still remains stereotyped as a male domain (Dickerson and Taylor 2000), especially among Poles who are rather a traditional nation with stereotypical views on gender roles, also in an entrepreneurial context.

Considering the above, entrepreneurial self-efficacy might be genderdependent, thus the level of entrepreneurial intentions might be genderdependent.

The summary of the theoretical discussion is displayed in Figure 1. 


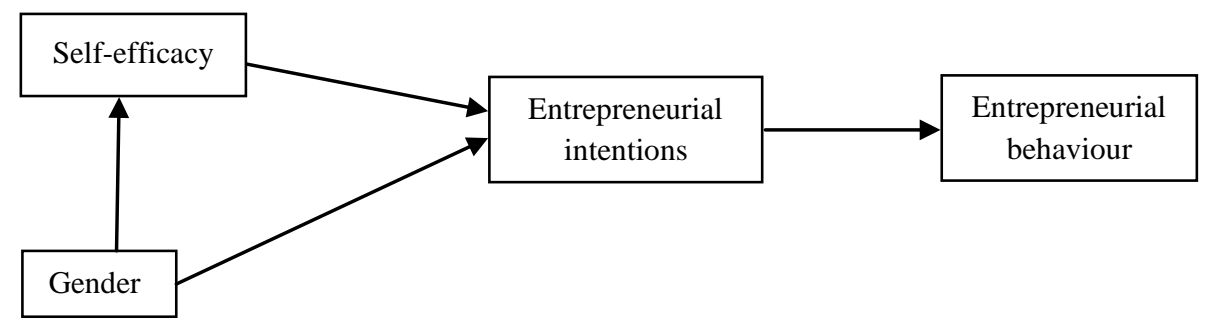

Figure 1. Research model

\section{METHODOLOGY}

In this section we describe and justify our methodological choices. We start by stating the hypothesis, then introduce the measures and methods, and finally present the sample.

\section{Hypothesis}

Gathering our theoretical considerations on entrepreneurial intentions, gender and self-efficacy leads us to the following central hypothesis:

Female students have lower self-efficacy than male students, which induces lower intentions towards venture creation,

supported by the following three auxiliary hypotheses:

Entrepreneurial intentions are higher among males than females.

Self-efficacy significantly affects the level of entrepreneurial intentions.

The level of self-efficacy among males is higher than among females.

To test our hypotheses we took data from a large study on students' entrepreneurial intentions conducted by the team of authors in 2012 at the University of Lodz, Poland. The study concerned entrepreneurial intentions in general and included questions referring to different elements of the entrepreneurial models of Ajzen and Shapero. We selected the questions referring to intentions and self-efficacy which were treated as a predictor of entrepreneurial intentions. Intentions were measured on a six-item scale. Self-efficacy was measured on a seven-item scale. Each item was measured on a five-point Likert scale.

\section{Measures}

- Measuring entrepreneurial self-efficacy

Investigating the interplay between self-efficacy and intentions first demands choosing their measures. Self-efficacy is usually measured by psychometric scales. The most popular scales are the ones developed by Chen et al. (1998), DeNoble et al. (1999) and McGee et al. (2009). The 
scales might be based on skills needed in venture creation or the abilities to cope with uncertainty and risk. Moberg (2013), after comparing the three most popular scales, distinguished six basic constructs that should be included in the questionnaire relating to entrepreneurial self-efficacy. These are respectively: creativity, planning/management, marshalling, human resource management, financial literacy and managing ambiguity. However, we agree with Noble et al. (1999), and in our view technical, functional and managerial skills are not specifically entrepreneurial but relate more to effective managers. Hence, our measures are related to concepts traditionally connected with entrepreneurship.

The self-efficacy scales have been accused of being one-dimensional, making entrepreneurial self-efficacy less reliable (Moberg 2013). To avoid that, the questions on self-efficacy were differentiated and concerned with the perception of: own skills (like business planning), personal traits, gained knowledge and barriers (lack of ability to accumulate funding, lack of sufficient support) in the context of perceiving oneself as a future entrepreneur. Although the questionnaire was distributed among students who had experienced some education in business, the statements were constructed in a way to avoid discipline specific jargon (Moberg 2013).

\section{- Measuring entrepreneurial intentions}

Entrepreneurial intentions were measured by the level of accordance with the sentences relating to individuals' considerations and determinations to become an entrepreneur, possession of entrepreneurial ideas, and strength of choice.

\section{Method}

We tested the hypotheses by using the two means t-test, the coefficient of correlation test, the Chi-squared independence test and the Mann-Whitney U test. The Statistica 8.0 programme was used for the calculations. The t-test and the Mann-Whitney U test were used to verify the central hypothesis, the coefficient of correlation test was used to verify the influence of self-efficacy on entrepreneurial intentions and we also conducted the Chi-squared independence test to check the dependency between entrepreneurial intentions and gender. We decided to use the Mann-Whitney U test as a support for a "classical", parametric two means t-test because the MannWhitney $\mathrm{U}$ test is the strongest non-parametric alternative to the t-student test (Stanisz 2006). Using the nonparametric Chi-squared independence test is also justified since the number of observations was over 100 and each cell of the contingency table was over 10 (see Jóźwiak and Podgórski 2006).

The empirical research agenda was as follows: 
1) Measuring and comparing the level of entrepreneurial intentions among females and males

2) Measuring and comparing the level of self-efficacy among females and males

3) Examining the influence of self-efficacy on entrepreneurial intentions

4) Examining the dependency between entrepreneurial intentions and gender

5) Examining the dependency between self-efficacy and gender

6) Comparing the distribution of entrepreneurial intentions and selfefficacy in the female and male samples

\section{Sample}

The study was conducted in spring 2012, on a group of students at the Faculty of Economics and Sociology of the University of Lodz in Poland. The University of Lodz, founded in 1945, is a state-owned university, with 12 faculties and over 47,000 students. The sample included randomly selected students studying at the Faculty of Economics and Sociology: Economics, Finance and Accountancy, International Studies, Logistics, European Studies, IT studies. We received 232 responses (138 females, and 94 males). All responses were deemed valid. The respondents were between 20 and 28 years old, but over 92 per cent of respondents were between 21 and 24 years old. Over 66 per cent of the answers were given by bachelor level students and over 33 per cent by master level students.

Due to our limited budget and the availability of our local students, we did not distribute the questionnaire at any other universities and thus the generalization of our conclusions should be made carefully. However, the size of our sample was big enough to use the statistical methods described below and to generalize conclusions on the whole population of students at the University of Lodz.

\section{ANALYSIS AND FINDINGS}

By using the two means t-test $[\mathrm{t}(230)=3.44$, one sided $p$-value $=0.00034]$ we found that female students expressed significantly lower entrepreneurial intentions than male students. The average values ${ }^{2}$ for the entrepreneurial intentions in the male and female sample are displayed in Table 1.

\footnotetext{
${ }^{2}$ The values of particular variables were calculated by averaging the values of the sentences in the questionnaires. The quasi-continuous variables were obtained in this way.
} 
Table 1

Values of entrepreneurial intentions ${ }^{*}$ in the female and male groups

\begin{tabular}{c|c|c}
\hline Parameter of the $\boldsymbol{I}$ distribution & Women (138) & Men (94) \\
\hline Mean & 3.178 & 3.590 \\
\hline Median & 3.167 & 3.833 \\
\hline Standard deviation & 0.812 & 1.006 \\
\hline Mode & 2.333 & 4.000 \\
\hline First Quartile & 2.500 & 2.833 \\
\hline Third Quartile & 3.833 & 4.333 \\
\hline Kurtosis & -0.662 & -0.733 \\
\hline Minimum & 1.333 & 1.167 \\
\hline Maximum & 5.000 & 5.000 \\
\hline
\end{tabular}

Source: own study, statistics calculated with Statistica software ver. 8.0

* Cronbach's Alpha value for this variable was over 0,889 signifying the reliability of the data. In particular, Cronbach's Alpha value for female students was lower than the corresponding Cronbach’s Alpha value for male students (0,853 and 0,911 respectively).

Then we compared the self-efficacy values in both considered gender groups by using the two means t-test $[t(230)=1.174$, one sided $p-$ value $=0.12]$. According to the results, there is no statistically important difference in the self-efficacy level between males and females $(\alpha=0.05)$.

Table 2

Values of self-efficacy in the female and male groups

\begin{tabular}{c|c|c}
\hline Parameter of the $V$ distribution & Women (138) & Men (94) \\
\hline Mean & 3.302 & 3.379 \\
\hline Median & 3.333 & 3.333 \\
\hline Standard deviation & 0.513 & 0.455 \\
\hline Mode & 3.500 & 3.333 \\
\hline First Quartile & 3.000 & 3.167 \\
\hline Third Quartile & 3.667 & 3.667 \\
\hline Kurtosis & 0.204 & 0.815 \\
\hline Minimum & 1.667 & 2.000 \\
\hline Maximum & 4.333 & 4.167 \\
\hline
\end{tabular}

Source: based on self-study, statistics calculated with Statistica software ver. 8.0 
We also checked the influence of self-efficacy on entrepreneurial intentions. We conducted the coefficient of correlation test. The results are as follows:

For the whole sample:

- $\quad$ Pearson's correlation coefficient value: $r_{X Y}=0.305$

- $t(232)=4.857$

- $\quad p<0.05$

For the female sample:

- Pearson's correlation coefficient value: $r_{X Y}=0.326$

- $t(138)=4.021$

- $\quad p<0.05$

For the male sample:

- Pearson's correlation coefficient value: $r_{X Y}=0.265$

- $t(138)=2.636$

- $\quad p<0.05$

As we can see, all correlations are statistically significant $(\alpha=0.05)$. The analysis of Pearson's correlation coefficient shows that the correlation between variables is positive but weak. However, we can notice that the influence of self-efficacy on entrepreneurial intentions was weaker among males than females.

We also conducted the Chi-squared independence test to check the dependency between entrepreneurial intentions and gender $\left[\chi^{2}=17.069\right.$, $d f=3, p=0.00062]$, as well as the dependency between self-efficacy and gender [ $\left.\chi^{2}=4.775, d f=3, p=0.189\right]$. The results proved that the relation between gender and entrepreneurial intentions is statistically important, so we may conclude that entrepreneurial intentions are gender dependent. However, gender seems not to influence self-efficacy. Hence, the results from our two means t-test are confirmed.

In the final stage, we checked the distribution of entrepreneurial intentions and self-efficacy in both the female and male samples. The reasoning behind this was as follows: if gender determines entrepreneurial intentions and selfefficacy, then the distribution of entrepreneurial intentions and self-efficacy should be significantly different in the female and male samples. We used the Mann-Whitney U Test to determine this as it is the strongest non-parametric alternative of the t-student test. 
$V(f)$ - the distribution of self-efficacy in the female sample

$V(m)$ - the distribution of self-efficacy in the male sample

$I(f)$ - the distribution of entrepreneurial intentions in the female sample

$I(m)$ - the distribution of entrepreneurial intentions in the male sample

\section{Test 1}

$$
\begin{aligned}
& H_{0}: I(f)=I(m) \text { vs } H_{1}: I(f) \neq I(m) \\
& U=9.5 \\
& p=0.047
\end{aligned}
$$

At the significance level of 5\%, we reject $H_{0}$ hypothesis and accept the alternative one stating that the distributions of entrepreneurial intentions are significantly different for the considered females and males.

\section{Test 2}

$$
\begin{aligned}
& H_{0}: V(f)=V(m) \text { vs } H_{1}: V(f) \neq V(m) \\
& U=21.5 \\
& p=0.668
\end{aligned}
$$

There is no reason to reject $H_{0}$ hypothesis stating that the distribution of self-efficacy is significantly different in the female and male samples.

Summing up our results, the level of entrepreneurial intentions is genderdependent and men present higher intentions towards venture creation than woman. However, entrepreneurial self-efficacy is not related to gender and self-efficacy is not a major factor shaping entrepreneurial intentions. Therefore the central hypothesis of our research has not been confirmed. The reason for the lower intentions among women is not significantly connected with their self-efficacy.

\section{CONCLUSIONS}

The idea of the study was to understand better the nature of female and male entrepreneurship by studying the relation between intentions, selfefficacy and gender. We were interested in the specifics of female entrepreneurship and its antecedents. The results proved that males show substantially higher mean entrepreneurial intentions than females. However, contrary to what we expected, gender was not mediated by self-efficacy but directly affected entrepreneurial intentions. This raises two questions. The first is what, if not the self-efficacy factor, makes women less entrepreneurial, and the second is what is the contextual meaning of the results. 
Answering the first question demands further research on entrepreneurial intentions and their determinants. The weak influence of self-efficacy on entrepreneurial intentions among females and males needs further interpretation. Similar findings about no difference in self-efficacy between females and males were achieved for example by Sequeira et al. (2005) and Mueller and Conway Dato-On (2007). However, earlier studies, like Chen et al. (1998) and Bandura (1992) showed some differences. In that sense, it might be interpreted as a good sign that nowadays society and possibly entrepreneurship education provide equality in the perception of self-efficacy among females and males, especially if we treat gender as socially constructed and thus influenced by society and entrepreneurship education. Therefore, self-efficacy does not explain the differences in the level of entrepreneurial intentions between genders. If self-efficacy, being part of the perceived feasibility in intentions models, has a very limited power, then maybe perceived desirability plays an important role in shaping entrepreneurial intentions. This would mean that society and education concentrate on teaching individuals how to be feasible but do not enhance their entrepreneurial desires, or not in an equal way for women and men.

Referring the findings to a Polish context brings some new insights into research. When looking at other European Union countries, Poland shows the highest level of perceived capabilities and one of the highest level of entrepreneurial intentions. Also, most of the respondents indicate entrepreneurship as a good career choice (GEM 2012). At the same time, Poland experiences the highest level of necessity-driven entrepreneurship (measured as \% of TEA ${ }^{3}, 41 \%$ for Poland when the EU average is $21 \%$ ). In Poland, becoming an entrepreneur is still perceived as a more masculine type of career. At the same time official statistics indicate that Poland is one of the countries with the highest disparity in the early-stage entrepreneurship level of men and women. According to the GEM 2012 report, thirteen per one hundred men and only six per one hundred women are involved in the creation or operation of young businesses. Thus, gender differences in the level of entrepreneurial intentions might be the result of female underrepresentation among entrepreneurs. However, when we take into consideration differences between men and women in terms of type of entrepreneurship, it shows that women rather than men start their business

\footnotetext{
${ }^{3}$ In GEM terminology, TEA is Total Early-Stage Entrepreneurial Activity. TEA is measured as the percent of population of the age of 18-64 who are nascent entrepreneurs or who have operated a venture for a maximum of 3 years and a half.
} 
because they want to seize the perceived opportunities. Female opportunity entrepreneurship (measured as \% of TEA) is $63 \%$, compared to $48 \%$ in the male sample. The entrepreneurship statistics for Poland also do not support the idea that the perceived capabilities influence the level of the opportunity entrepreneurship.

Table 3

Paradoxes of Polish entrepreneurship

\begin{tabular}{l|c|c}
\hline \multicolumn{1}{c|}{ GEM indicators } & Poland & $\begin{array}{c}\text { European Union } \\
\text { (average) }\end{array}$ \\
\hline Perceived opportunities & 20 & 31 \\
\hline Perceived capabilities & 54 & 42 \\
\hline Entrepreneurship as a good career choice & 68 & 58 \\
\hline $\begin{array}{l}\text { Entrepreneurial intentions (among the non-entrepreneur } \\
\text { population) }\end{array}$ & 22 & 13 \\
\hline Male TEA (\% adult population) & 13 & 10 \\
\hline Female TEA (\% adult population) & 6 & 5 \\
\hline Male Opportunity TEA (\% male TEA) & 48 & 75 \\
\hline Female Opportunity TEA (\% female TEA) & 63 & 74 \\
\hline Male Necessity TEA (\% male TEA) & 44 & 21 \\
\hline Female Necessity TEA (\% female TEA) & 34 & 21 \\
\hline
\end{tabular}

Source: GEM 2012 Statistics

\section{Implications and further research recommendations}

The study has implications for entrepreneurship education. The findings have relevance for academics involved in teaching entrepreneurship. If women report lower entrepreneurial career intentions and self-efficacy is not the universal key to boost entrepreneurial intentions, we have to think again how to redesign our teaching interventions. It does not mean that we do not have to try to enhance the self-efficacy of our students, but rather that we should not cease in our efforts to discover other ways to increase entrepreneurial intentions. Also, the differences between females and males confirm that gender-sensitive education has its reason.

The results support the most recent stream of research that highlights the diversity of students and their learning processes. The study contributes to the discussion on entrepreneurship education from the viewpoint of gender. However, it is limited to one country under investigation, therefore what could be recommended for future research is to extend the study to other countries, for example the Baltic States, to include a broader socio-cultural context. 
Due to the sample profile, the results of the study may also be embedded into a broader discussion on generation $\mathrm{Y}$ (also known as the millennial generation), i.e. the generation of people born after 1980. The differences of our results in comparison to earlier research may be explained by the distinctly different behaviour, values and attitudes of a new generation of students.

\section{REFERENCES}

Ajzen, I., The Theory of Planned Behavior, "Organizational Behavior and Human Decision Processes” 50, pp. 179-211, 1991.

Ajzen, I., Perceived Behavioural Control, Self-Efficacy, Locus of Control, and the Theory of Planned Behaviour, “Journal of Applied Social Psychology”, 32, pp. 665-683, 2002.

Bandura, A., Self-Efficacy Mechanism in Human Agency, “American Psychologist” 37(2), pp. 122-147, 1982.

Bandura, A., Exercise of Personal Agency through the Self-Efficacy Mechanisms [in:] Schwarzer, R. (ed.), Self-Efficacy: Thought Control of Action. Hemisphere, Washington, DC, 1992.

Bandura, A., Human Agency in Social Cognitive Theory, “American Psychologist” 44, pp. 1175-1184, 1989.

Bandura, A., Self-Efficacy in Changing Societies. Cambridge University Press, 1995.

Barbosa, S., Gerhardt, M., Kickul, J., The Role of Cognitive Style and Risk Preference on Entrepreneurial Self-Efficacy and Entrepreneurial Intentions, "Journal of Leadership \& Organizational Studies”, 13(4), pp. 86-104, 2007.

Bird, B. J., Implementing Entrepreneurial Ideas: The Case for Intention, "Academy of Management Review” 13, pp. 442-453, 1988.

Boyd, N.G., Vozikis, G. S., The Influence of Self-Efficacy on the Development of Entrepreneurial Intentions and Actions, "Entrepreneurship Theory and Practice" 18(4), pp. 63-77, 1994.

Chen, C. C., Greene, P. G, Crick, A., Does Entrepreneurial Self-Efficacy Distinguish Entrepreneurs from Managers?, “Journal of Business Venturing”, 13, pp. 295-316, 1998.

DeNoble, A.F., Jung, D., Ehrlich, S.,Entrepreneurial Self-Efficacy: the Development of a Measure and its Relationship to Entrepreneurial Action. Frontiers of Entrepreneurship Research, Babson College, Wellesley, MA, 1999.

Dickerson, A., Taylor, A., Self-Limiting Behaviour in Women: Self-Esteem and Self-Efficacy as Predictors, “Group and Organization Management”, 25 (2), pp. 191-210, 2000.

GEM 2010 Global Report

GEM 2012 Global Report

Iakovleva, T., Kolvereid, L., An Integrated Model of Entrepreneurial Intentions, "International Journal of Business and Globalisation” 3(1), pp. 66-80, 2009.

Jóźwiak, J., Podgórski, J., Statystyka od podstaw [Basics of Statistics]. Polskie Wydawnictwo Ekonomiczne, Warszawa, 2006. 
Krueger, N. F., Brazeal, D. V., Entrepreneurial Potential and Potential Entrepreneurs, "Entrepreneurship Theory and Practice” 18(3), pp. 91-104, 1994.

Langowitz, N., Minniti, M., The Entrepreneurial Propensity of Women, "Entrepreneurship: Theory \& Practice”, 31(3), pp. 341-364, 2007.

McGee, J. E. M., Peterson, S., Mueller, L., Sequeira, J. M., Entrepreneurial Self-Efficacy: Refining the Measure, "Entrepreneurship Theory and Practice”, 33(4), 2009.

Liñán, F., Intention-based Models of Entrepreneurship Education, "Piccolla Impresa/Small Business”, Issue 3, pp. 11-35, 2004.

Moberg, K., An Entrepreneurial Self-Efficacy Scale with a Neutral Wording [in:] Fayolle, A., Kyrö, P., Mets, T., Venesaar, U. (eds.) Conceptual Richness and Methodological Diversity in Entrepreneurship Research: Entrepreneurship Research in Europe.Edward Elgar, 2013.

Mueller, S. L., Conway Dato-On, M., Gender-Role Orientation as a Determinant of Entrepreneurial Self-Efficacy, “Journal of Developmental Entrepreneurship”, Vol. 18(1), pp. 3-20, 2008.

Nwankwo, B. E, Marire, M. E., Kanu, G. C., Balogun, S. K., Uhiara, A. C.,Gender-Role Orientation and Self-Efficacy as Correlates of Entrepreneurial Intention, "European Journal of Business and Social Sciences”, Vol. 1, No. 6, pp. 09-26, October 2012.

Scherer, R., Brodzinski, J., Wiebe, F., Entrepreneurial Career Selection and Gender: A Socialization Approach, “Journal of Small Business Management”, 28(2), p. 37, 1990.

Shapero, A., Sokol, L., The Social Dimensions of Entrepreneurship [in:] Encyclopedia of Entrepreneurship. Prentice-Hall, Inc., Englewood Cliffs, New Jersey, 1982.

Sequeira, J. M., McGee, J. E., Mueller, S. L., An Empirical Study of the Effect of Network Ties and Self-Efficacy on Entrepreneurial Intentions and Nascent Behavior. Proceedings of the Southern Management Association 2005 Meeting, Charleston, South Carolina, 2005.

Stajkovic, A. D., Luthans, F., Self-Efficacy and Work-Related Performance: A MetaAnalysis, "Psychological Bulletin”, 124(2), pp. 240-261, 1988.

Stanisz, A., Przystępny kurs statystyki z zastosowaniem STATISTICA PL na przykładach z medycyny [Accessible Statistics Course Using STATISTICA PL]. StatSoft, Kraków, 2006.

Wagner, J., What a Difference a Y Makes - Female and Male Nascent Entrepreneurs in Germany, “Small Business Economics”, 28(1), pp. 1-21, 2007.

Wilson, F., Kickul, J., Marlino, D., Gender, Entrepreneurial Self-Efficacy, and Entrepreneurial Career Intentions: Implications for Entrepreneurship Education, “Entrepreneurship Theory and Practice”, 31, pp. 387-406, 2007.

Xiaohong, Q., Prior Experience, Social Network, and Levels of Entrepreneurial Intentions, “Management Research Review”, Vol. 35, Issue 10, pp. 945-957, 2012.

Zhao, H., Seibert, S. E., Hills, G. E., The Mediating Role of Self-efficacy in the Development of Entrepreneurial Intentions, “Journal of Applied Psychology”, 90, pp. 1265-1272, 2005.

Received: June 2013, revised: May 2014

Acknowledgment: The paper is a result of a project financed by National Science Center in Poland (DEC-2011/01/D/HS4/01956) 